\section{TREATMENT OF IRREDUCIBLE INTUSSUSCEPTION}

\author{
BY \\ J. D. T. JONES, M.S., F.R.C.S. \\ Assistant Surgeon, Royal Victoria Infirmary, Newcastle- \\ upon-Tyne
}

Until recently the mortality of irreducible intussusception, whatever the method of treatment employed, was depressing. Thus Ladd and Gross (1941) stated: "In any large series of cases there will always be some individuals for whom resection of an intussusception must be employed. In babies under 1 year of age this carries an extremely high mortality, averaging around $75 \%$ or more." In McNab's (1948) opinion, " as soon as the intussusception in a child becomes irreducible the mortality rate associated with the treatment rises to $80 \%$." In the last few years, however, the picture has changed very considerably; for example, Gross and Ware (1948) report 11 recoveries in 14 resections, Aird $(1949,1952) 13$ survivals from 17 resections, and White and Dennison (1952) 12 recoveries in 16 cases treated by ileocolostomy.

As Aird remarks, these improved results are having a most beneficial effect upon the morale of surgeons, and if it is felt that resection is at least reasonably hopeful as a method of treatment the surgeon is more inclined to proceed to it at a stage when the child has not been intoxicated by the squeezing of infected material into its circulation. It is perhaps permissible to suggest that the time has now come when a child who has to have an irreducible intussusception resected should be expected to survive. The purpose of this communication is to present a method of dealing with these cases by resection and early restoration of bowel continuity, a method which has been found safe and satisfactory, and which, for reasons that will be discussed, is believed to have several advantages over previously described methods. The technique employed was initially used by me in dealing with the first irreducible case in this present series, and, with minor variations, it has been used for all subsequent cases.

\section{Material}

In this report are presented the results of nine cases of irreducible intussusception treated by this method, with eight recoveries and one death. These cases were treated between January 1, 1951, and December 31, 1952. During the same period 82 cases of reducible intussusception were treated by operative reduction with no deaths.

A further 12 cases which occurred are not included in this series for the following reasons : six cases had intussusceptions on admission which underwent spontaneous reduction shortly after admission without operation and without mortality; six cases belonged to the subacute or chronic group with symptoms lasting from 5 to 35 days : operative reduction of these was performed with no deaths.

TABLE I.-Distribution of Reducible Cases According to Time Interval Between Onset of Symptoms and Admission to Hospital

\begin{tabular}{c|c|c|c|c|c}
\hline $\begin{array}{c}0-6 \\
\text { Hours }\end{array}$ & $\begin{array}{c}6-12 \\
\text { Hours }\end{array}$ & $\begin{array}{c}12-24 \\
\text { Hours }\end{array}$ & $\begin{array}{c}24-48 \\
\text { Hours }\end{array}$ & $\begin{array}{c}48-72 \\
\text { Hours }\end{array}$ & $\begin{array}{c}3-5 \\
\text { Days }\end{array}$ \\
\hline 18 & 11 & 19 & $2 ?$ & 6 & 6 \\
\hline
\end{tabular}

Table II.-Results in All Cases Operated Upon Between January 1, 1951, and December 31, 1952

\begin{tabular}{cc|c|c|c}
\hline & & No & Deaths & $\%$ Age Mortality \\
\hline $\begin{array}{cc}\text { Reducible } . . \\
\text { Irreducible }\end{array}$ & $\cdots$ & 82 & 0 & 0 \\
\hline Total .. & $\cdots$ & 9 & 1 & $11 \cdot 1$ \\
\hline
\end{tabular}

In the total of 103 cases accepted for admission the overall mortality was $0.97 \%$.

It must be emphasized that in our opinion results of this kind can be achieved only if there is close and continuous co-operation between surgeon and paediatrician : the treatment of these children demands not only a competent surgical technique but also skilled, devoted, and often prolonged and arduous post-operative medical and nursing care. The majority of these children have been operated upon by four members of the surgical staff of the Royal Victoria Infirmary who are of senior status and who are at the same time engaged in general surgical practice. We believe that this policy has been an important factor in lowering mortality.

\section{Diagnosis}

Little can be added to the admirable account already given by Morrison and Court (1948) from this school. It is, of course, a matter for regret that the diagnosis should have been delayed so long in some of our cases, but the delay has often appeared due not so much to lack of care or neglect on the part of the family doctor as to a failure to consider the possibility of intussusception at all. The reason for this is undoubtedly the comparative rarity of the condition, and it is possible that a policy of closer integration between consultant and practitioner as advocated by Spence and Court (1950) would diminish the number of late cases occurring. Lateness in diagnosis is, however, not the only factor responsible ; there is no constant relationship between duration of symptoms and irreducibility, and, as White and Dennison have pointed out, another factor of equal if not greater importance is the degree of fixation or otherwise of the caecum and ascending colon. A mobile colon will allow the apex of the intussusception to travel onwards with relatively little interference with its blood supply, and in these cases, even after 24 to 48 hours or longer, the intussusception may be easily reducible and the bowel viable. With a fixed colon, on the other hand, the mesentery of the entering bowel becomes obstructed at an early stage, with consequent oedema and congestion, and these cases may prove irreducible even within the first 12 to 24 hours.

We do not favour the use of diagnostic barium enemata, believing that the manipulations involved have a definite adverse effect on the child's general condition; the occasions on which the diagnosis is in doubt are very few, and in these circumstances we prefer the safety and certainty of an exploratory laparotomy.

\section{Treatment}

These children are ill, dehydrated, and obstructed, and operation should not be considered until an intravenous plasma drip has been erected and is running satisfactorily, and some at any rate of the dehydration has been corrected; this must be done even though it may mean delaying operation for three or four hours, or longer. A nasal catheter must be passed before operation and the stomach emptied and kept empty.

Premedication consists in the administration of $1 / 480 \mathrm{gr}$. $(0.14 \mathrm{mg}$.) atropine into the drip for a child under 1 year of age ; anaesthesia is induced by nitrous oxide and ether, and maintained by oxygen and ether with some nitrous oxide ; mephenesin has been used on occasion. The essentials are that there should be a good airway, that respiration should not be too depressed, and that there should be 
adequate relaxation. We think it desirable that the anaesthetist should take an active part in the conduct of the case throughout, in the decision regarding the best time to operate, and in the management of any post-operative complications that may occur. The abdomen is opened by a right paramedian rectus-splitting incision; as much of the reduction as possible is performed intraperitoneally; and the mass is then withdrawn from the abdomen, covered with warm saline packs, and gently compressed to try to reduce congestion and oedema. Further attempts at reduc-

TABLE III.-Cases Treated by Two-stage Resection and Anastomosis

\begin{tabular}{|c|c|c|c|c|c|c|}
\hline No. & Age & \multicolumn{2}{|c|}{ Duration } & Type & $\begin{array}{c}\text { Extent } \\
\text { of Resection }\end{array}$ & Result \\
\hline 1 & $4 \mathrm{mths}$ & \multicolumn{2}{|c|}{42 hours } & Ileo-colic & Right hemicol- & Satisfactory \\
\hline 2 & $7 \frac{1}{2}$, & 10 & , & Ileo-ileal & 5 in. $(12.7 \mathrm{~cm})$. & ", \\
\hline 3 & 3 , & 59 & , & Ileo-co'ic & $\begin{array}{l}3 \text { in }(7 \cdot 7 \mathrm{~cm} .) \\
\text { terminal ileum; } \\
\text { whole co.on } \\
\text { down to pelvic }\end{array}$ & Died \\
\hline 4 & $2 \frac{9}{4 r s}$ & & , & Ileo-ileal & 9 in. $(22.8 \mathrm{~cm})$. & Satisfactory \\
\hline 5 & 3 mths & 28 & , & Ileo-colic & $\begin{array}{l}\text { Right hemicol- } \\
\text { ectomy }\end{array}$ & , \\
\hline $\begin{array}{l}6 \\
7 \\
8\end{array}$ & $\begin{array}{r}11 \\
5 \\
4\end{array}$ yrs & $\begin{array}{l}86 \\
77 \\
22\end{array}$ & ,", & Ileo-ileal, start- & 12 in. $\left(30 \cdot \ddot{5}^{\prime} \mathrm{cm}.\right)$ & ", \\
\hline 9 & $4 \frac{1}{2} \mathrm{mths}$ & & ", & $\begin{array}{l}\text { ing with in- } \\
\text { vagin a ted } \\
\text { Meckel's di- } \\
\text { verticulum } \\
\text { Ileo-ileo-colic }\end{array}$ & $\begin{array}{c}8 \text { in. }(20 \cdot 3 \mathrm{~cm} .) \\
\text { terminal ileum }\end{array}$ & " \\
\hline
\end{tabular}

Cases 2 and 8 were operated on by Professor F. H. Bentley ; Case 4 by Mr. F. D. Hindmarsh; Case 9 by Mr. D. J. Tibbs; and Cases 1, 3, 5, 6, and 7 by me.

tion are then made, but as soon as it is evident that these are not going to succeed, or if it is obvious that the bowel is necrotic or gangrenous, then resection is proceeded with. A good deal of experience is required to enable the surgeon to recognize irreducibility at as early a stage as possible; if he does not do so, but persists with attempts at reduction, the bowel is devitalized still further, the child's general condition deteriorates, and it is less well able to withstand the next stage.

The resection is performed in the usual way and the abdominal wall is closed snugly round the two adjacent limbs of the exteriorized loop; the limbs are not sutured together, nor are they attached to the abdominal wall. After protecting the skin incision, bowel clamps are applied, the devitalized bowel is removed, and a small Paul's tube is tied into each of the two open bowel ends.

The second stage of the operation is performed approximately 48 hours later. The first step is to tie a stout ligature tightly around each limb of bowel between the Paul's tube and the skin surface; the bowel is then cut across just beyond this ligature and the two Paul's tubes with the fringe of bowel around each are removed. The short stumps of bowel, together with the surrounding skin, are then thoroughly cleansed with cetrimide and the skin sutures removed. Having done this, the surgeon rescrubs and proceeds with the next steps of the operation; the abdomen is reopened, and the two limbs of bowel are freed from the abdominal wall and from one another. The terminal inch or so of each limb tends to be rather oedematous and friable as a result of its exteriorization and does not hold sutures well; this short cuff of bowel on either limb is therefore removed and the bowel ends are closed with two layers of continuous catgut sutures; continuity of the bowel is then restored by side-to-side anastomosis. The abdomen is closed in layers. A drain is not used unless there is doubt concerning the viability of the bowel.

Ideally, the best treatment for these cases would be primary resection and anastomosis, but in our experience this procedure has given the worst results. We are averse to using suture methods in the presence of an acute obstruction, and we have found that decompression of the bowel for about 48 hours improves tone, reduces oedema and congestion, and makes it better able to hold sutures. Of even greater importance is the fact that the very ill child cannot stand a primary resection and anastomosis: where this operation has been done in the past, death has been due not to a leakage from the anastomosis but to acute constitutional failure associated with collapse, and in some cases with hyperpyrexia, and it has usually occurred very soon after the termination of the operation. The two-stage operation does the minimum to the ill child, and it defers the "injury" of the anastomosis until the child is better able to withstand it. We have found a 48-hour period between the two stages sufficient, and we like to proceed with the second stage before the Paul's tubes drop out, with the resultant soiling of the skin and possible infection of the wound. We have not used a "spur" type of doublebarrelled enterostomy; we dislike this procedure in infants because of the occasional difficulties associated with its closure and the consequent delay in re-establishing normal bowel function. The average length of stay in hospital in our eight surviving cases was 17.1 days. At the time of discharge, in each case, the wound was healed and bowel function normal.

It has often been stated that while vascular obstruction will lead to gangrene of the inner and middle layers of an intussusception the ensheathing layer is not affected and remains viable. In two of our cases, however, this was not so. In Case 3, duration 54 hours, the apex of the intussusception was at the anal margin, and was black and gangrenous. The child was very ill and shocked, with a tense distended abdomen. Operation was performed five hours after admission. Reduction was at first relatively easy, but when the apex had reached the middle of the descending colon-and thus far no force had been used-it was noted that there were multiple greenish-yellow well-demarcated oval necrotic areas about $1.5 \mathrm{~cm}$. in greatest diameter in the ensheathing layer. These areas started below in the upper pelvic colon, and were all situated on the medial wall of the gut, close to the mesenteric attachment. There were narrow bridges of normal-looking bowel between the areas, and the remainder of the bowel circumference also looked normal. As more of the intussusception was reduced, more necrotic areas became visible, and it was therefore decided to resect the whole of the large bowel to a point below the most distal of the visible areas of necrosis. This was done, and 36 hours later continuity of the bowel was restored by a side-to-side anastomosis of ileum to the stump of pelvic colon. The child's condition remained satisfactory for six days, but a faecal fistula then developed owing to giving way of the anastomosis. Repeated attempts were made to close this fistula, but without success, and, despite an unremitting battle, the child eventually died on the sixtyeighth day after admission.

It is probable that the breakdown of the anastomosis was due to interference with the blood supply to the remaining portion of large bowel, although this was not apparent at the time. If this was the case, it is difficult to see what other procedure could have re-established normal bowel function and allowed the child to survive.

In Case 6, duration 86 hours, the apex of the intussusception was in the pelvic colon. It reduced easily at first, but the terminal three inches $(7.7 \mathrm{~cm}$.) was irreducible, and the bowel was black and gangrenous. The terminal ileum, caecum, and ascending colon were resected. The reduced part of the ensheathing layer appeared normal at this time, and there had been no tearing of the serosa during reduction. Forty-eight hours later, however, at the second stage, we found three areas of greenish-yellow necrosis in the transverse colon : the most proximal area was $3 \mathrm{~cm}$. from the divided end of the colon, and around it there was a small collection of pus; the most distal area was just proximal to the splenic flexure; and the third area was in the middle 
of the transverse colon. Each area was oval in shape in the long axis of the bowel, measuring approximately 2.5 by $1.5 \mathrm{~cm}$., and situated on the medial wall close to the mesenteric attachment; each was sharply circumscribed, and the rest of the bowel appeared normal. A cuff of colon containing the most proximal area was resected, the area near the splenic flexure was oversewn and invaginated with a single layer of continuous catgut suture, and the third area was locally excised and the resultant defect in the bowel wall used as a stoma for the ileo-colic anastomosis. Recovery was uneventful.

These two cases indicate that ischaemic necrosis of the ensheathing layer can occur. We do not believe that the trauma associated with reduction had any part in the production of these changes, and for this reason we are loath to employ any method of primary anastomosis, with or without resection of the irreducible portion of bowel. The possibility of these changes occurring is a further factor influencing the choice of 48 hours as the optimum time interval between the two stages. Delay much beyond this time may be associated with perforation of one of the necrotic areas, with either a generalized or a localized peritoneal infection.

\section{Post-operative Treatment}

Consideration of the detailed management of the postoperative period is outside the scope of this article, but stress must be laid on the great importance of this phase of treatment, and tribute paid to the skill and enthusiasm of our paediatric colleagues, who have supervised the day: to-day care of these children. This care entails attention to the state of the child's nutrition, hydration, and oxygenation; correction of blood electrolyte changes; the use of antibiotics, sedatives, or stimulants as required; and, most important of all, frequent clinical assessments of the child's condition and progress. If these requirements cannot be fulfilled, then the child's prospects of survival are correspondingly reduced.

\section{Summary}

Ninety-one cases of intussusception occurring in infants and young children are presented. Of these cases 82 were reduced at operation with no deaths. Nine cases were irreducible and were treated by a twostage procedure of resection and early restoration of bowel continuity with one death.

The reasons for employing the two-stage operation are discussed.

Attention is drawn to the possibility of ischaemic changes occurring in the outer layer of the intussusception in late cases.

Stress is laid on the importance of correct preoperative and post-operative management of these ill children.

It is a pleasure to acknowledge the help received from Sir James Spence and members of his staff, particularly Dr. Donald Court and Dr. Hugh Jackson, in the preparation of this report. I should also like to thank Mr. John Gilmour for his constant encouragement and advice.

\section{REFERENCES}

Aird, I. (1949). Companion in Surglcal Studies, p. 677. Livingstone, Edinburgh.

(1952). British Encyclopaedia of Surgical Practice: Surgical Progress, p. 185. Butterworth, London.

Gross, R. E., and Ware, P. F. (1948). New Engl. J. Med., 239, 645.

Ladd, W. E., and Gross, R. E. (1941). Abdominal Surgery in Infancy and Childhood, p. 117. Saunders, Philadelphia.

McNab, G. H. (1948). British Encyclopaedia of Surgical Practice, 5, 165. Butterworth, London.

Morrison, B., and Court, D. (1948). British Medical Journal, 1, 776.

Spence, J. C., and Court, D. (1950). Ibid., 2, 920.

White, M., and Dennison, W. M. (1952). Brit. J. Surg., 40, 137.

\section{THE ACCIDENT-PRONE IN GENERAL PRACTICE*}

\author{
BY
}

\author{
R. M. McGREGOR, T.D., M.B., Ch.B. \\ From a General Practice \\ Hawick, Scotland
}

Accidents are usually regarded as a hospital problem. While investigating the diseases encountered in family practice the importance of this subject to the general practitioner impressed me and seemed worthy of record.

My practice is situated in a small manufacturing town in the Scottish Borders. It is partly rural and partly suburban. The suburban population are mainly employed in the manufacture of high-class hosiery and tweed. These industries are not the cause of many accidents, so it is not of industrial injuries that I write. The extensive rural areas are concerned with sheep farming and, to a less extent, dairy produce. The total population of the area is about 21,000 , of whom 17,500 live in the town and about 3,500 in the rural areas. My share of this population is 2,562 , and of these 716 live in the country.

TABLE I.-Population at Risk

\begin{tabular}{|c|c|c|c|c|c|}
\hline \multicolumn{3}{|c|}{ Age } & $\mathbf{M}$ & $\mathbf{F}$ & Total \\
\hline $\begin{array}{lll}0-4 \text { years } \\
5-14 \quad, & \\
15-44 & , & \\
45-64 & & \\
65+ & & \\
\text { Not stated } & \end{array}$ & $\begin{array}{l}\cdots \\
\cdots \\
\cdots \\
\ldots\end{array}$ & $\begin{array}{l}\cdots \\
\cdots \\
\cdots \\
\ldots\end{array}$ & $\begin{array}{r}102 \\
160 \\
515 \\
273 \\
155 \\
1\end{array}$ & $\begin{array}{r}102 \\
146 \\
520 \\
385 \\
199 \\
4\end{array}$ & $\begin{array}{r}204 \\
306 \\
1,035 \\
658 \\
354 \\
5\end{array}$ \\
\hline & & & 1,206 & 1,356 & 2,562 \\
\hline
\end{tabular}

Table I shows the age distribution of these 2,562 patients - a distribution which corresponds with what one would expect in a rural district. There is a relative deficit in pre-school and school age groups and an excess in the older age groups, taking Scotland as a whole.

\section{Accidents Encountered}

During the first two years of the National Health Service 401 of those 2,562 patients were involved in 468 accidents. I have classified those accidents according to the type of TABLE II.-Type of Accident (All Cases)

\begin{tabular}{|c|c|c|c|c|c|}
\hline Diagnosis & $\mathbf{M}$ & $\mathbf{F}$ & Total & $\underset{\%}{\text { Hawick }}$ & $\underset{\%}{\text { Stirling }}$ \\
\hline $\begin{array}{l}\text { Bruises } \\
\text { Sprains and strains } \\
\text { Fractures } \\
\text { Open wounds } \\
\text { Foreign bodies } \\
\text { General effects of interna } \\
\quad \text { causes } \\
\text { Burns and scalds } \ldots \\
\text { Head injuries } \\
\text { Crushing injuries } \\
\text { Other forms of violence }\end{array}$ & $\begin{array}{r}59 \\
60 \\
32 \\
56 \\
19 \\
\\
3 \\
17 \\
9 \\
8 \\
19\end{array}$ & $\begin{array}{r}47 \\
47 \\
20 \\
16 \\
7 \\
5 \\
16 \\
5 \\
3 \\
20\end{array}$ & $\begin{array}{r}106 \\
107 \\
52 \\
72 \\
26 \\
8 \\
8 \\
33 \\
14 \\
11 \\
39\end{array}$ & $\begin{array}{r}22 \cdot 65 \\
22 \cdot 86 \\
11 \cdot 11 \\
15 \cdot 38 \\
5 \cdot 55 \\
1 \cdot 71 \\
7 \cdot 05 \\
2 \cdot 99 \\
2 \cdot 35 \\
8 \cdot 35\end{array}$ & $\begin{aligned} 10 \cdot 13 \\
9 \cdot 58 \\
19 \cdot 06 \\
38 \cdot 49 \\
8 \cdot 20 \\
0 \cdot 18 \\
4 \cdot 14 \\
5 \cdot 34 \\
2.03 \\
2 \cdot 85\end{aligned}$ \\
\hline Total & 282 & 186 & 468 & $100 \cdot 0$ & $100 \cdot 0$ \\
\hline
\end{tabular}

injury, and for this purpose have adopted the classification used by Lockhart (1950) when he made a survey of the accident cases treated as out-patients or admitted to Stirling Hospital. This permits me to compare hospital figures with those of general practice, which, of course, includes cases treated in hospital or at home.

*This investigation formed part of the work undertaken while receiving the Ernest Hart Memorial Scholarship of the British Medical Association. I feel it should be more widely known that such scholarships are available to general practitioners who are prepared to do research in general practice. 